\title{
Recurrent Clostridium difficile diarrhoea
}

\author{
L Kyne, C P Kelly
}

Clostridium difficile diarrhoea is a common iatrogenic nosocomial disease. Fortunately, most affected patients respond well to medical therapy that includes discontinuation of the inciting antibiotic and treatment with metronidazole or vancomycin. ${ }^{1}$ However, despite successful treatment of initial episodes, $15-25 \%$ will have recurrence of diarrhoea following withdrawal of specific antibiotic therapy. ${ }^{12}$ Treatment of this form of $C$ difficile disease can be particularly problematic.

Approaches to management include conservative therapy, treatment with specific anti- $C$ difficile antibiotics, use of anion binding resins, therapy with microorganisms (probiotics), and immunoglobulin therapy (table 1).

Table 1 Approach to management of recurrent Clostridium difficile diarrhoea

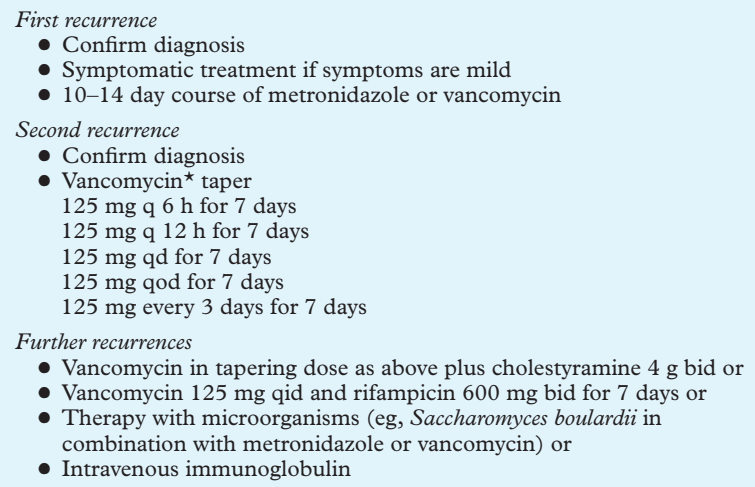

- Vancomycin in tapering dose as above plus cholestyramine $4 \mathrm{~g}$ bid or

- Vancomycin $125 \mathrm{mg}$ qid and rifampicin $600 \mathrm{mg}$ bid for 7 days or

- Therapy with microorganisms (eg, Saccharomyces boulardii in

combination with metronidazole or vancomycin) or

- Intravenous immunoglobulin

^ Metronidazole may be substituted for vancomycin although there are no published data regarding its efficacy in this treatment regimen q 6 h, every $6 \mathrm{~h}$; qd, every day; qod, every other day; bid, twice daily; qid, four times daily.

(Table adapted with permission from Linevsky JK, Kelly CP. Clostridium difficile colitis. In: Lamont JT, ed. Gastrointestinal infections: diagnosis and management. New York: Marcel Dekker, 1997:293-325).

\section{First recurrence}

\section{CONSERVATIVE THERAPY}

Conservative management of recurrent diarrhoea is preferable to retreatment with metronidazole or vancomycin as these agents perpetuate disturbance of the normal intestinal flora predisposing patients to further recurrences. ${ }^{2}$ However, it is often difficult to withhold antibiotic therapy as many patients with recurrent dis-

Harvard Medical School, Gerontology and Gastroenterology Divisions, Beth Israel Deaconess Medical Center, 330 Brookline Avenue, Boston, MA 02215, USA

Correspondence to: C P Kelly. ciaran_kelly@caregroup.harvard.edu ease are not able to tolerate ongoing diarrhoea. Persistent or worsening diarrhoea caused by recurrent $C$ difficile infection is a clear indication for active treatment.

RETREATMENT WITH SPECIFIC ANTI-C DIFFICILE ANTIBIOTICS

The most common therapy for recurrent $C$ difficile diarrhoea is a second course of the same antibiotic used to treat the initial episode. ${ }^{2}$ In one large observational study, $92 \%$ of patients with recurrent $C$ difficile diarrhoea responded successfully to a single repeated course of therapy, usually with metronidazole or vancomycin. ${ }^{3}$ Unfortunately, despite successful treatment of a recurrent episode, up to $65 \%$ of patients may have multiple recurrences. ${ }^{4}$

\section{Second and further recurrences}

A variety of treatment schedules have been suggested for patients with multiple recurrences of $C$ difficile diarrhoea. One approach is to give a prolonged course of vancomycin (or metronidazole) using a decreasing dosage schedule followed by pulse therapy. ${ }^{5} \mathrm{~A}$ combination of vancomycin and rifampicin was used successfully in a small uncontrolled study of seven patients with relapsing disease. ${ }^{6}$ Anion exchange resins, such as cholestyramine, bind $C$ difficile toxins and may be used in conjunction with antibiotics to treat frequent relapsers. $^{2}$ However, as cholestyramine may bind vancomycin as well as toxins, it should be taken at least 2-3 hours before or after vancomycin.

Biotherapy (therapy with microorganisms or "probiotics") is an attractive approach to the management of recurrent $C$ difficile diarrhoea because it aims to restore the "colonisation resistance" of the normal colonic flora. Several agents and routes of administration have been evaluated, including brewer's or baker's yeast (Saccharomyces cerevisiae) taken by mouth, Lactobacillus $G G$ given as a concentrate in skim milk, a mixture of colonic bacteria in saline administered as a rectal infusion, fresh faeces administered as a rectal enema, oral administration of non-toxigenic $C$ difficile, and Saccharomyces boulardii given in capsule form. ${ }^{12}$ Unfortunately, many of these studies have been small, open labelled, and uncontrolled.

$S$ boulardii is a non-pathogenic yeast that has been reported to reduce the incidence of antibiotic associated diarrhoea. A randomised, double blinded, placebo controlled trial demonstrated that $S$ boulardii $(500 \mathrm{mg}$ twice a day for four weeks) in combination with metronidazole or vancomycin significantly reduced recurrences compared with placebo in patients with multiple episodes of $C$ difficile diarrhoea (recurrence rate $35 \% v$ $65 \% ; p=0.04){ }^{4}$ 


\section{THERAPY UPDATE}

There is now substantial evidence that the immune response to $C$ difficile toxins plays a major role in determining host susceptibility to disease. ${ }^{78}$ Several investigators have found that serum antibody levels against $C$ difficile toxins are low in patients with recurrent $C$ difficile diarrhoea. ${ }^{8}$ In a study of six children with relapsing $C$ difficile colitis, Leung et al found that these children had low serum levels of IgG antibody against toxin A. Treatment with normal pooled intravenous gamma globulin $(400 \mathrm{mg} / \mathrm{kg}$ every three weeks) that contains IgG anti-toxin A was associated with a marked increase in serum antitoxin antibody levels and resolution of recurrent $C$ difficile diarrhoea. ${ }^{9}$ Although this approach to the management of recurrent $C$ difficile diarrhoea is promising, further controlled studies are required before gamma globulin can be recommended as therapy for this condition.

In summary, the management of recurrent $C$ difficile diarrhoea can be a challenge to healthcare providers. Several treatment approaches have been recommended but experience to date is largely anecdotal. Further randomised controlled clinical trials are necessary to evaluate the efficacy of biotherapy and immunotherapy. Future approaches to the control of nosocomial $C$ difficile infection and subsequent recurrence may involve active or passive immunisation of at risk individuals. ${ }^{8}{ }^{10}$ Until that time, the basic principals of management should involve (a) treatment of $C$ difficile diarrhoea and (b) reduction of the susceptibility of the individual to $C$ difficile reinfection by judicious use of antibiotics and attention to infection control issues.

Supported by the US National Institutes of Health grant AG00971 (LK).

1 Kelly CP, Pothoulakis C, LaMont JT. Clostridium difficile colitis. N Engl f Med 1994;330:257-62.

2 Fekety R. Guidelines for the diagnosis and management of Clostridium difficile-associated diarrhea and colitis. American College of Gastroenterology, Practice Parameters Committee. Am f Gastroenterol 1997;92: 739-50.

3 Olson MM, Shanholtzer CJ, Lee JT Jr, et al. Ten years of prospective Clostridium difficile-associated disease surveillance and treatment at the Minneapolis VA Medical Center, 1982-1991. Infect Control Hosp Epidemiol 1994;15:371-81.

4 McFarland LV, Surawicz CM, Greenberg RN, et al. A randomized placebo-controlled trial of Saccharomyces boulardii in combination
with standard antibiotics for Clostridium difficile disease. $\mathscr{f} A M A 1994$; 271:1913-18.

5 Tedesco FJ, Gordon D, Fortson WC. Approach to patients with multiple relapses of antibiotic-associated pseudomembranous colitis. Am $\mathcal{F}$ Gastroenterol 1985;80:867-8.

6 Buggy BP, Fekety R, Silva J Jr. Therapy of relapsing Clostridium difficileassociated diarrhea and colitis with the combination of vancomycin and rifampin. F Clin Gastroenterol 1987;9:155-9.

7 Kyne L, Warny M, Qamar A, et al. Asymptomatic carriage of Clostridium difficile and serum levels of IgG antibody against toxin A. N Engl f Med 2000;342:390-7.

8 Kyne L, Warny M, Qamar A, et al. Association between antibody response to toxin A and protection against recurrent Clostridium difficile diarrhoea. Lancet 2001;357:189-93.

9 Leung DY, Kelly CP, Boguniewicz M, et al. Treatment with intravenously administered gamma globulin of chronic relapsing colitis induced by Clostridium difficile toxin. I Pediatr 1991;118:633-7.

10 Kyne L, Kelly C. Prospects for a vaccine for Clostridium difficile. BioDrugs 1998;10:173-81. 